\title{
Os Grupos Escolares no Brasil e o foco dado a disciplina Matemática: uma revisão bibliográfica
}

Zenildo Santos9o

Claudinei de Camargo Sant'Ana

\section{Resumo}

Resumo: Nossa produção versa sobre a criação dos grupos escolares no Brasil e o foco dado a disciplina Matemática, com o objetivo de situar numa perspectiva histórica, o ensino de Matemática no ensino primário. Nesses termos, a metodologia utilizada foi uma breve revisão bibliográfica sobre a criação dos grupos escolares, servindo de base o texto de Valente (1999) e Souza (1998). É possível explanar que os Grupos Escolares surgiram em São Paulo, no início da República e se disseminou por todo o país como modelo de renovação do ensino primário. Quanto a disciplina Matemática, essa passa a existir a partir do ano de 1930, quando Euclides Roxo, na época, diretor do Colégio Pedro II, propõe uma reforma, inicialmente dirigida a esse colégio, onde a matemática escolar que até então era trabalhada em três campos distintos, passaria por uma unificação em uma única disciplina escolar intitulada Matemática, posteriormente, a reforma foi estendida para as demais escolas do país.

Palavras-chave: Ensino de Matemática; História da Educação Matemática Escolar; Grupos Escolares. 


\title{
The implantation of School Groups in Brazil and the focus on the Mathematical discipline
}

\author{
Zenildo Santos ${ }^{91}$ \\ Claudinei de Camargo Sant'Ana
}

\begin{abstract}
Abstract: Our production is about the creation of school groups in Brazil and the focus given to the Mathematics discipline, aiming to place in a historical perspective, the teaching of Mathematics in primary education. In these terms, the methodology used was a brief bibliographical review on the creation of school groups, based on the text by Valente (1999) and Souza (1998). It is possible to explain that the School Groups appeared in São Paulo, at the beginning of the Republic and spread throughout the country as a model for the renewal of primary education. As for the Mathematics discipline, it began to exist in 1930, when Euclides Roxo, then director of the Pedro II College, proposed a reform, initially addressed to this college, where school mathematics, which until then had been worked in three different fields, would undergo a unification in a single school subject Mathematics, later, the reform was extended to the other schools of the country.
\end{abstract}

Key-words: Mathematics Teaching; History of School Mathematics Education; School Groups. 


\section{Introdução}

O presente artigo integra uma pesquisa de mestrado, fase inicial, junto ao Programa de Pós-Graduação Stricto Sensu em Educação Científica e Formação de Professores (PPGECFP) da Universidade Estadual do Sudoeste da Bahia/UESB, que tem como objetivo investigar como era desenvolvido o ensino de Matemática e identificar a cultura escolar dos grupos escolares do município de Aiquara BA no período compreendido entre os anos 1965 a 1985. Apoiando-se no referencial teórico da história cultural (Chartier, 2002), da cultura escolar (Julia, 2001) e da história das disciplinas escolares (Chervel, 1990) e em autores que discutem a criação dos grupos escolares no país.

Alinhado a pesquisa, este texto tem como objetivo apresentar uma revisão bibliográfica sobre a implantação dos grupos escolares no país, que segundo Souza (1998, p.16) esse modelo escolar foi projetado para ser "uma organização administrativa e pedagógica complexa, concebida nos princípios da racionalidade científica e na divisão do trabalho", e foi considerado o principal difusor dos valores republicanos, "sendo preciso torná-los evidentes, exibi-los, solenizá-los".

Os grupos escolares criados no final do século XIX, consistiam em instituições de ensino primário graduado com novas metodologias para o ensino sendo inserida algumas exigências na pedagogia escolar, tais como: oficinas, bibliotecas, mobiliário escolar, pátio para recreio e utilização de material escolar.

Para Souza (1998) algumas das inovações introduzidas nessa época permanecem até hoje nas nossas escolas, desse modo, eis a pertinência e relevância deste texto em discutir a implantação dos grupos escolares e a sua contribuição para o modelo de ensino que temos na atualidade.

Ainda, com base no pensamento da autora, cabe acrescentar que a instauração dos grupos escolares no Brasil ocorre simultaneamente a disseminação do ideário de educação escolarizada como redentora da humanidade. Os grupos escolares foram criados para atender as necessidades da sociedade brasileira que passava por um processo de modernização, advindos da instauração da Regime Republicano.

\section{Histórico da criação dos Grupos Escolares no Brasil}

Com a derrubada da Monarquia, surge no Brasil um novo sistema de poder, a República (1889-1930). Dentre as muitas ações e discursos que os líderes que assumiram o poder do novo sistema de governo fizeram circular, estavam aqueles que propunham modificações no modo como o Ensino Primário deveria ser organizado. 
Coube aos republicanos repensar e esboçar uma escola que atendesse os ideais que propunham construir uma nação baseada em pressupostos civilizatórios, inspirados na matriz europeia que tinham na escolarização do povo iletrado um de seus pilares de sustentação.

O modelo de educação primária vigente no período monárquico consistia em classes isoladas ${ }^{92}$, heterogêneas e funcionavam de maneira precária, em locais improvisados, comumente na própria residência dos docentes, sob a regência de um único professor. Segundo Saviani (2010, p. 172) "essas escolas isoladas, uma vez reunidas, deram origem, ou melhor, foram substituídas pelos grupos escolares”.

Assim surge os grupos escolares no país, que inicialmente foram criados no Estado de São Paulo, reunindo características da escola graduada, um modelo utilizado no final do século XIX em diversos países da Europa e nos Estados Unidos para possibilitar a implantação da educação popular.

Em Souza (2008, p. 41), temos que

O modelo de escola graduada, amplamente em voga nos países europeus e nos Estados Unidos desde meados do século XIX, compreendia um tipo de organização nos moldes da escola graduada. Contratando com a escola unitária regida por um só professor, o grupo escolar logo se converteu em mais um dos símbolos de renovação do ensino primário no Estado de São Paulo e no Brasil.

Esse modelo escolar que já que possuía turmas seriadas, foi utilizado no final do século XIX em diversos países da Europa e nos Estados Unidos para possibilitar a implantação da educação popular, também recebeu influência das repercussões da Revolução Francesa, que propagava a ideia de que, para se alcançar a civilização, era preciso instruir a população.

Em conformidade Saviani (2006), esse padrão se constituiu um fenômeno tipicamente urbano, já que no meio rural ainda predominou as escolas isoladas por muito tempo. Silva (2014) aduz que a nomenclatura Grupo Escolar, foi utilizada no território nacional por ser o tipo de escola que mais se aproximou do modelo de escola graduada reunindo características da arquitetura (construção de prédios próprios, com o espaço dividido em várias salas) e no que diz respeito aos aspectos pedagógicos (classificação dos alunos, divisão do trabalho docente, seriação, racionalização dos programas, etc.).

Com a experiência exitosa, o modelo de educação primária instalado no Estado de São Paulo serviu de referência para a disseminação para outros estados brasileiros que, gradativamente, foram implantando. No Rio de Janeiro em 1897, no Maranhão e Paraná em 1903, em Minas Gerais no ano de 1906, no Rio Grande do Norte, Espírito Santo e Santa 92 Conforme o Artigo 22 da Lei $n^{0}$ 1006/1913, editada no Estado da Bahia, a escola isolada é uma escola
regida por um professor, funccionando em um prédio. (Bahia, 1913) ISSN 2526-2882 
Catarina em 1908, no Mato Grosso em 1910, na Paraíba em 1916, em Sergipe 1916, em Goiás em 1918 e no Piauí em 1922.

Os grupos escolares possuíam características das escolas graduadas, já que possuíam turmas seriadas.

A escola graduada fundamentava-se essencialmente na classificação dos alunos pelo nível de conhecimento em agrupamentos supostamente homogêneos, implicando a constituição das classes. Pressupunha, também, a adoção do ensino simultâneo, a racionalização curricular, controle e distribuição ordenada dos conteúdos e do tempo (graduação dos programas e estabelecimento de horários), a introdução de um sistema de avaliação, a divisão do trabalho docente e um edifício escolar compreendendo várias salas de aula e vários professores. (SOUZA, 2006, p. 114)

Esse modelo de foi considerado um símbolo de modernização do ensino, por toda a parte onde foi implantado, em acordo mútuo com perspectivas em relação ao desenvolvimento social e econômico da época.

Além de prever uma composição administrativo-pedagógica que estabelecia modificações profundas e precisas na didática, no currículo e na distribuição espacial dos edifícios, o grupo escolar era uma escola moderna e o seu modelo previa edifícios, livros didáticos, mobiliário, além de docentes qualificados. Nesse contexto, destaca-se a figura do professor primário, que começou a desempenhar as novas funções que lhes foram designadas, sofrendo intensas modificações em sua maneira de trabalhar.

Em Souza (2006, p.116), "a escola graduada pressupôs a organização metódica e sistemática do conhecimento a ser transmitido na escola primária”. Com a finalidade de construir atividades adequadas as novas metodologias de ensino instruídas pela moderna pedagogia, foi necessário desenvolver projetos de estruturação nos espaços escolares.

O ensino primário passou a ter duração de quatro anos, integrando um programa enciclopédico com matérias que proporcionavam uma educação integral. Nos grupos escolares, a estrutura pedagogia previa a utilização do método intuitivo, o qual usava diversificados materiais didáticos, laboratórios e museus.

É válido, acrescentar que teve grande influência no aspecto pedagógico nos grupos escolares o método intuitivo oriundo da Alemanha e difundido amplamente pela Europa na segunda metade do século XIX, que conforme afirma Saviani (2010, p.138-139) ficou,

conhecido como lições de coisas, foi concebido com o intuito de resolver o problema da ineficiência do ensino diante de sua inadequação às exigências sociais decorrentes da revolução industrial que se processara entre o final do século XVIII e meados do século XIX. Ao mesmo tempo, essa mesma revolução industrial viabilizou a produção de novos materiais didáticos como suporte físico do novo método de ensino. Esses materiais, difundidos nas 
exposições universais, realizadas na segunda metade do século XIX com a participação de diversos países, entre eles o Brasil, compreendiam peças do mobiliário escolar; quadros negros parietais; caixas para ensino de cores e formas; quadros do reino vegetal, gravuras, cartas de cores para instrução primária; aros, mapas, linhas, diagramas, caixas com diferentes tipos de objetos como pedras, metais, madeira, louças, cerâmica, vidros; equipamentos de iluminação e aquecimento; alimentação e vestuário etc.

O Método Intuitivo considerava que se deveria ensinar, indo do particular para o geral, do concreto para o abstrato, valorizava o ensino pela intuição, isto é, a base de todo aprendizado se dava pelos sentidos e da observação.

Foi criado com base nos estudos de Pestalozzi (1781, 1801) e foi divulgado amplamente por vários educadores, entre eles Norman Allison Calkins que publicou, nos Estados Unidos, em 1861 o livro Primary object lessons for training the senses and developing the faculties of children. A manual of elementary instruction for parents and teachers, que logo conseguiu enorme sucesso.

Aqui no Brasil, destaca-se como defensores, Rui Barbosa, cujos princípios do método foram apresentados nos seus Pareceres e chegou a traduzir o livro de Calkins (1861), Primeiras Lições de Coisas e Caetano de Campos que aplicou na organização da escolas-modelo e dos grupos escolares.

Nos grupos escolares, os princípios pedagógicos a serem trabalhados pelo professor integram a concepção que a Escola Nova, mais tarde, veio considerar com pedagogia tradicional e embasava-se, os princípios:

a) Simplicidade, análise e progressividade - o ensino deve começar pelos elementos mais simples(...)

b) Formalismo - o ensino chega ao encadeamento de aspectos rigorosamente lógicos (...)

c) Memorização - (...) A medida do conhecimento do aluno é dada pela sua capacidade de repetir o que foi ensinado pelo professor.

d) Autoridade - A escola elabora um sistema de prêmio e castigos (...) visando a garantir que a organização pedagógica se funde na autoridade do professor. e) emulação - A ideia de dever, a necessidade de aprovação e o sentimento do mérito são desenvolvidos para manter a atividade escolar, e completam-se, desse modo, o princípio da autoridade.

f) Intuição - (...) exige o oferecimento de dados sensíveis a observação e percepção do aluno (...). (SAVIANI, 2010, p. 172)

Dos alunos era exigida uma disciplina rígida, comprometendo-se com a assiduidade, asseio, ordem, obediência etc. O tempo escolar passou a ser controlado através do calendário e as escolas adotaram práticas como os exames finais, exposições escolares, comemorações de datas cívicas e realização de festas de encerramento do ano letivo. Os desfiles patrióticos dos grupos escolares eram vistos como transmissores de uma linguagem coletiva, capaz de 
expressar concomitantemente múltiplos planos simbólicos que os levam a ser identificados como uma grande festa.

Azevedo e Santos (2017, p.316-317) também referenciam que a realização destas festas dava visibilidade aos grupos escolares e a organização mobilizavam as ruas, avenidas e praças de uma determinada localidade e havia:

Demonstração de hinos, desfiles artísticos, cânticos, beleza e a organização bem como disciplina dos alunos fardados, limpos e arrumados eram exemplos do que se podia ver nas solenidades. Era como se fossem grandes cerimônias que abriam as portas dos grupos escolares para toda a sociedade, transformando e mudando a rotina das pessoas.

Esses dispositivos de racionalização administrativa e pedagógica, necessários para o desenvolvimento da sociedade capitalista, principalmente nos processos de urbanização e industrialização, foi considerado, um projeto cultural a favor da nação, o qual educava mais do que instruía.

[...] Ela reportava a uma clara concepção de ensino; educar pressupunha um compromisso com a formação integral da criança que ia muito além da simples transmissão de conhecimentos úteis dados pela instrução e implicava essencialmente a formação do caráter mediante a aprendizagem da disciplina social - obediência, asseio, ordem, pontualidade, amor ao trabalho, honestidade, respeito às autoridades, virtudes morais e valores cívico patrióticos necessários à formação do espírito de nacionalidade. (SOUZA, 2006, p. 127)

Nesse sentido, a educação passou a ser considerada instrumento essencial na preparação do cidadão para o trabalho e para a prática política. Assim, em Aranha (2006) verificamos que o projeto político republicano tinha o objetivo de oferecer educação para todos, no entanto esse projeto apresentava-se dualista, pois enquanto possibilitava a continuidade nos estudos para as crianças e jovens oriundas da elite, para o povo o ensino era restrito à educação elementar e profissionalizante.

Foi dessa forma que surgiram as escolas públicas e gratuitas. Sendo o ensino primário e profissional de responsabilidade dos governos estaduais e o ensino secundário do governo federal.

Os Grupos Escolares foram extintos em $1971 \mathrm{e}$

Ao longo da década de 1970 foram transformando-se em escolas estaduais de $1^{\mathrm{O}}$ grau, e o sentido de escola primária foi redefinido na educação brasileira. [...]. Durante boa parte do século XX, os grupos escolares constituíram no país estabelecimentos de ensino que conferiam uma identidade institucional à escola primária. (SOUZA, 2006, p. 153), 
Diante o exposto, segue-nos ainda, compreender o contexto histórico que os grupos escolares foram criados. Sobre essa assertiva, Julia (2001) opina que não se pode estudar a cultura escolar sem observação minuciosa das relações de conflito ou paz que ela mantém. $\mathrm{O}$ autor destaca a importância de estudar as culturas que são contemporâneas e descreve a cultura escolar como:

um conjunto de normas que definem conhecimentos a ensinar e condutas a inculcar, e um conjunto de práticas que permitem a transmissão desses conhecimentos e a incorporação desses comportamentos; normas e práticas coordenadas a finalidades que podem variar segundo as épocas (finalidades religiosas, sociopolíticas ou simplesmente de socialização). (JULIA, 2001, p. 10 , grifos do autor).

Dessa maneira, a cultura escolar se estabelece com pessoas que mantem relações no interior da escola e é oriunda das diversas atividades existentes na escola (festas, atividades extraescolares, sua dinâmica de organização, etc.) bem como do contexto que a escola está inserida.

Sobre o exposto, Chervel (1990, p. 187), aduz que

Pode-se globalmente supor que a sociedade, a família, a religião experimentaram, em determinada época da história, a necessidade de delegar tarefas educacionais a uma instituição especializada, que a escola e o colégio devem sua origem a essa demanda, que as grandes finalidades educacionais que emanam da sociedade global não deixaram de evoluir com as épocas e os séculos, e que os comanditários sociais da escola conduzem permanentemente os principais objetivos da instrução e da educação aos quais ela se encontra submetida.

Percebe-se que o autor ao referir à existência de determinadas finalidades originadas do processo social atribui importante indicação das origens da demanda social da institucionalização, ou seja, há finalidades educacionais e instrucionais que podem ser religiosas, sócio-políticas ou culturais. Nessa conjuntura é necessário discorrer o contexto educacional que antecede o período de implantação dos Grupos Escolares, dando visibilidade ao ensino de Matemática.

\section{A Educação do Brasil Colônia à República Velha}

As práticas escolares que remontam do período colonial à república, se reportam aos duzentos anos de existência dos colégios jesuítas. No período colonial brasileiro (1500 a 1822), 
a educação escolar no Brasil foi influenciada pelo predomínio dos jesuítas, pelas reformas pombalinas 93 e pela reforma feita por D. João VI quando trouxe a Corte Real para o Brasil.

A educação, no período jesuítico propunha a formação integral do homem cristão e tinham um curso básico de Humanidades, com Filosofia e Teologia.

O ensino então ministrado pelos jesuítas podia ser considerado como público por ser mantido com recursos públicos 94 e pelo seu caráter de ensino coletivo, ele não preenchia dos demais critérios, já que as condições tanto materiais como pedagógicas, isto é, os prédios assim como a infra-estrutura, os agentes, as diretrizes pedagógicas, os componentes curriculares, as normas disciplinares e os mecanismos de avaliação se encontravam sob controle dos jesuítas, portanto, sobre domínio privado (SAVIANI, 2006, p. 16).

A educação formava o "homem culto" de Portugal, com tradição escolástica (os textos eram quase todos inspirados em São Tomás de Aquino), amor à autoridade, desinteresse pelas ciências e desprezo pelas atividades técnicas e artísticas. Esse plano de estudo ficou conhecido como Ratio Studiorum que constituía em um manual pedagógico com descrição de como os jesuítas deveriam ensinar.

Se o legado histórico nos remete aos duzentos anos de educação jesuítica do Brasil, nesse período praticamente era inexistente a instrução pública, a educação dos jesuítas, referendava-se no ensino de instrumento de cristianização e de sedimentação do domínio português, e que, não sobrevive à ação de Pombal.

Da expulsão da Companhia de Jesus em 1759, que o ensino escolar passa por uma reforma feita pelo Ministro de Estado de Portugal, o Marquês de Pombal que busca adaptar aquele país e suas colônias ao mundo moderno, sob a ótica político e cultural, implementando ideias próximas ao Iluminismo. De acordo Pinheiro (2002, p. 16), "o efeito das reformas pombalinas no Brasil consistiu, prioritariamente, na expulsão dos jesuítas, prioritariamente, na expulsão dos jesuítas, fato que levou à destruição de todo sistema colonial do ensino jesuítico."

Dessa reforma, nasceu o ensino público, ou seja, o ensino mantido pelo Estado. Saviani (2010, p. 107) afirma que "estas [reformas pombalinas] tinham como objetivo a criar a escola útil aos fins do estado em substituição àquela que servia aos interesses eclesiásticos”,

93 Importante marco na Historiografia da Educação Brasileira, instituída pelo o Marquês de Pombal, o primeiro ministro de Português, (1750-1777) Sebastião José de Carvalho e Melo. A reforma educacional pombalina culminou com a expulsão dos jesuítas precisamente das colônias portuguesas, tirando o comando da educação das mãos destes e passando para as mãos do Estado [...] Através do Alvará Régio de 28 de junho de 1759, o Marquês de Pombal, suprimia as escolas jesuíticas de Portugal e de todas as colônias ao expulsar os jesuítas da colônia e, ao mesmo tempo, criava as aulas régias ou avulsas de Latim, Grego, Filosofia e Retórica, que deveriam suprir as disciplinas antes oferecidas nos extintos colégios jesuítas. MARQUES DE POMBAL E A REFORMA EDUCACIONAL BRASILEIRA. Disponível em http://www.histedbr.fe.unicamp.br/navegando/periodo_pombalino_intro.html acesso em 20 abr. 2019. 94 Contava com incentivo e subsidio da Coroa Portuguesa. 
ou seja, rompe com o modelo jesútico que vigorava no Brasil. A partir de então, o Estado começa a realizar concursos, verificar a literatura que deveria a ser usada. Tem origem as aulas régias, aulas avulsas de latim, grego, filosofia e retórica, caindo em desuso o curso de Humanidades que desaparece por definitivo.

Afirma Miorim (1998, p. 83), que as aulas régias (“aulas avulsas”) eram ministradas em “[...] locais diferentes, sem nenhum a articulação entre elas e sem planejamento do trabalho escolar. Além disso, os professores recrutados para essas aulas não possuíam uma formação adequada". Já Saviani (2010, p. 108) contribui com a discussão acrescentando que "as aulas régias foram estendendo-se no Brasil, embora enfrentando condições precárias de funcionamento, salários reduzidos e frequentes atrasos no pagamento dos professores."

Com o estado de funcionamento das aulas régias, percebe-se que o governo enfrentou dificuldades para suprir a enorme lacuna que se abria na vida educacional, os salários dos mestres decaíram muito, o que desestimulava os seculares a se ocupar do exercício docente.

Corroborando com tal afirmativa, Azevedo (1996) apud Pinheiro (2002, p. 17) afirma "do ponto de vista formal, de organização, à 'unidade de sistema' sucedeu a fragmentação na pluralidade de aulas isoladas e dispersas. O ensino básico geral foi "pulverizado" nas "aulas de disciplinas isoladas (aulas régias), sem qualquer plano sistemático de estudos”. Saviani (2010, p. 108) ainda acrescenta que "as aulas régias eram sinônimos de escolas que, por sua vez, se identificavam com determinada cadeira, funcionando em regra, na casa dos próprios professores. Daí as expressões "aulas de primeiras letras", "aulas de latim”, "de grego", "de filosofia”, etc.”. Sobre a frequência a essas aulas o autor aduz que "os alunos podiam frequentar umas ou outras indiferentemente, pois além de avulsas, eram isoladas, isto é, sem articulação entre si” (SAVIANI, 2010, p. 108).

Vale mencionar que no Brasil colônia não existia imprensa muito menos instituições de ensino superior. As pessoas que possuíam recursos financeiros ou se destacavam nas escolas jesuíticas eram encaminhados para Portugal onde conseguiam fazer seus estudos e acabavam cursando a Universidade de Coimbra. Aqueles alunos que não possuíam recursos financeiros, mas se destacavam, encontravam nas ordens religiosas oportunidades de estudo. Normalmente eram aproveitados os considerados mais capazes para servir na metrópole e se encaminhavam para funções governamentais em Portugal ou no Brasil, ou ainda, para a carreira acadêmica ou eclesiástica.

Contudo, foi com a vinda da Corte Real Portuguesa para a Colônia em 1807 que o ensino no Brasil vivenciou mudanças significativas, aqui foram implantados inúmeros cursos profissionalizantes em nível médio e superior, bem como militares. A educação brasileira, enfim, ganha vulto e liberta-se gradualmente do ensino superior estrangeiro. D. João VI permitiu a abertura de escolas primárias em todo país e multiplicaram-se também as escolas 
secundárias de artes e ofícios. O ensino foi estruturado em três níveis: primário, secundário e superior. O primário era a "escola de ler e escrever", que passou a receber incentivo da Corte e aumentou suas "cadeiras" consideravelmente. O secundário permaneceu no regime das "aulas regias" e ganhou novas disciplinas.

Vale ressaltar que nesse período o Brasil era constituído basicamente de duas etnias, a de brancos, minoria absoluta e negros, mulatos, índios e descendentes. $\mathrm{O}$ acesso à escola era restrita aos brancos. Mattos e Silva (1995, p. 83) afirmam que:

O ideal normativizador - primeiro lusitanizante, depois em função de um padrão culto brasileiro - desencadeado no século XIX, não teve vez de se implantar efetivamente e generalizadamente no Brasil, restringindo-se apenas a uma minoria economicamente privilegiada e alguns quantos seres excepcionais, que romperam as limitações impostas pelo desenvolvimento sócio-econômico e cultural perverso do Brasil, desde as suas origens coloniais.

Nesse sentido, o século XIX herdou do período colonial um número muito reduzido de escolas régias de primeiras letras e um sistema de discriminação racial que prosseguiu até algumas décadas do século seguinte.

Quanto ao aspecto pedagógico das escolas de primeiras Letras, Saviani (2010, p. 129) confirma ainda a adoção do ensino mútuo, também conhecido como monitorial ou lancasteriano, que "baseava-se no aproveitamento dos alunos mais adiantados como auxiliares do professor no ensino de classes numerosas”. Nessa situação, o aluno monitor era investido na função docente, sob a supervisão de um professor, que reuniam seus alunos, de diferentes níveis de aprendizagem, em apenas uma sala de aula, sob a orientação de um professor.

\section{O Ensino da Matemática}

A história da educação no Brasil se inicia com a chegada dos jesuítas quando foram iniciadas as atividades escolares de ensino elementar com o propósito missionário e de política colonizadora - sendo ensinado apenas a leitura e a escrita nas primeiras escolas missionárias. Nesse contexto, a matemática foi relegada.

Na História da Matemática no Brasil no período colonial e pós-colonial observa-se que os governantes não demonstravam interesse pela Matemática, mesmo existindo alguns cursos de engenharia no país, especificamente no período republicano, mas nada que enfatizasse a importância de se formar um matemático.

Conforme Miorim (1998), no período colonial a publicação do Ratio Studiorum estabeleceu que as disciplinas Ciências e Matemática deveriam ser ensinadas apenas nos cursos de Ciências e Filosofia no nível superior, sem aprofundamento e em pequena quantidade. A autora afirma que “[...] a matemática nas escolas secundárias dos colégios 
jesuítas não existia, mesmo em cursos que exigiam alguns conhecimentos básicos da matemática” (MIORIM, 1998, p. 83).

Essa ausência se dava em face a concepção que os jesuítas tinham acerca da Matemática. Dainville (1978) citado por Valente (1999) descreve a opinião partilhada pelos jesuítas:

O estudo das ciências especulativas como a geometria, a astronomia e a física é um divertimento vão. Todos esses conhecimentos estéreis e infrutíferos são inúteis por ele mesmo. Os homens não nascem para medir linhas, para experimentar a relação entre ângulos e para empregar todo o seu tempo em considerar os diversos movimentos da matéria. Seu espírito é muito grande, a vida muito curta, seu tempo muito precioso para se ocupar de tão pequenas coisas (DAINVILLE, 1978, p. 332, apud VALENTE, 1999, p. 35).

Além de classificar a Matemática como uma ciência vã e muitos padres jesuítas apresentavam ressalvas ao seu conteúdo.

Muitos jesuítas não viam com bons olhos as matemáticas. Os estudos das relações misteriosas entre números e entre estes e as letras - a gematria inquietavam os religiosos. Além disso, a "busca de relações abstratas que, aparentemente, não ocupam nenhum lugar na escala dos seres" era encarada como uma ciência vã (MIORIM, 1998, p. 82).

Os excertos acima trazem a ideia que durante muitos anos, poder-se afirmar que a história das matemáticas escolares foi negligenciada no Brasil. Acresce-se a essa negligencia ou impedimento de difusão e desenvolvimento das matemáticas nesse período o fato de não existir professores na Companhia de Jesus.

De acordo, Valente (1999), o estudo de ciências (lógica, física, metafisica e ética) eram ministrados no curso de Artes. A Matemática era ministrada no curso de Física, porém negligenciada e seu conteúdo restringia a formar o raciocínio dos alunos antes de dotá-los dos elementos matemáticos para os cursos de física.

Para Silva (2011, p. 9) o ensino desse período constituía um ensino arcaico e percebia uma "ausência do ensino da Matemática de vanguarda de então, bem como a ausência de pesquisa científica básica atrelada ao ensino das Matemáticas. Percebemos que as cadeiras sobre Matemáticas abordavam o ensino de uma Matemática arcaica [...]”

Depois da expulsão dos Jesuítas, a educação matemática deu início ao um novo período de sua construção histórica. Sem a hostilidade jesuítica em relação Matemática, a disciplina poderia galgar destaque e firmar-se no cotidiano escolar brasileiro. Contudo como bem reflete Miorim (1998, p. 84), “a introdução legal das aulas de matemática não era uma garantia de que elas seriam populares e nem mesmo de que seriam realmente efetivadas na prática”. E isso, de fato, se concretizou na prática, uma vez que foi observada a baixa frequência ISSN 2526-2882

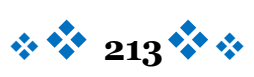


das aulas de aritmética, geometria e álgebra. Cabe ressaltar que essa premissa não foi exclusividade apenas da matemática, foi notada também em outras disciplinas das aulas régias. Acerca desse fato Miorim (1998, p. 87) relaciona a precarização do modelo e critica:

O estado lastimável em que se encontrara o ensino secundário no município da corte, reduzido a poucas aulas avulsas, sem nenhuma inspeção, incentivo ou orientação, onde os professores escolhiam seus horários de aula e os conteúdos de suas lições, e os alunos matriculavam-se e retiravam-se das aulas quando bem entendessem.

Quando o Brasil ficou Independente de Portugal, pensou-se na criação de uma escola pública, ato consolidado pela aprovação da Lei das Escolas de Primeira Letras, de 1827. De acordo a Lei, no período Imperial, as escolas funcionariam em cidades, vilas e lugares mais populosos. $\mathrm{O}$ artigo $6^{\circ}$ retrata o papel dos professores neste novo modelo de ensino:

Art. $6^{\circ}$ Os professores ensinarão a ler, escrever, as quatro operações de aritmética, prática de quebrados, decimais e proporções, as noções mais gerais de geometria prática, a gramática de língua nacional, e os princípios de moral cristã e da doutrina da religião católica e apostólica romana, proporcionados à compreensão dos meninos; preferindo para as leituras a Constituição do Império e a História do Brasil. (BRASIL, LEI DE 15 DE OUTUBRO DE 1827)

Nesse modelo de ensino o estudo da matemática ainda é fragmentado por área e a praticidade da disciplina é presente quando se elenca o aprendizado das quatro operações de aritmética, prática de quebrados, decimais e proporções, as noções mais gerais de geometria prática.

A Lei de 15 outubro de 1827, ditava as diretrizes para funcionamento dessas escolas, sendo interessante notar que diferenciava a educação para meninos e meninas, determinando inclusive escolas separadas para os dois sexos.

Para as meninas o currículo dispõe o aprender a ler, escrever, as quatro operações aritméticas, incluindo-se o ensino de práticas importante para a economia doméstica. Já o currículo para os meninos envolvia: ler, escrever, as quatro operações aritméticas, prática de quebrados, decimais e proporções, noções gerais de geometria, gramática da língua nacional, moral cristã e doutrina católica.

Observamos que no currículo para as meninas a geometria e a prática de quebrados foram eliminadas. Ainda, a Lei remonta que escolas para meninas existiriam nas localidades mais populosas e seriam dirigidas por professoras.

No início do período republicano, o conhecimento matemático era disseminado por meio das disciplinas geometria, álgebra, aritmética e trigonometria. Essas disciplinas eram oferecidas nos cursos primário e secundário de forma isoladas e fragmentadas. Os registros

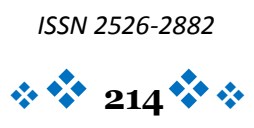


históricos apontam também a oferta nos cursos profissionalizantes de artilharia e fortificações, com destaque para a geometria espacial, cuja finalidade era utilizada na fabricação de bombas, lançamento de projéteis. A ênfase das escolas deste período era preparar os alunos para os demais cursos superiores. O ensino foi fortemente influenciado pelas teorias positivistas de Augusto Comte e foi inspirado por estes princípios.

Em 1891, com a Proclamação da República e a promulgação da Constituição de 1891, Benjamim Constant elaborou uma reforma de ensino, que no entender de Giles (1987, p. 288):

Benjamim Constant tenta substituir o currículo de teor acadêmico-humanista por um programa de estudos mais ampliado e abrangente, incluindo estudos científicos, de acordo com as inspirações positivistas do seu ator, Augusto Comte. Também propõe a seriação do ensino e uma organização maior do conjunto do programa de estudos.

Como houve resistência a essa reforma, visto que governantes e educadores passaram a dar ênfase às questões cívicas e nacionalistas, Ghiraldelli Jr. (1994, p. 86), afirma que "a legislação era clara: a escola deveria contribuir para a divisão de classes e, desde cedo, separar pelas diferenças de chances de aquisição cultural, dirigentes e dirigidos. [...], e, além disso, fornecer aos adolescentes um ensino patriótico e humanista".

No entender de D’Ambrósio (1999, p.7), "no curso do século XX houve uma abertura da academia a novas formas de saber e de fazer, sobretudo arte, literatura, religiões, culinária, música e mesmo medicina. Mas pouquíssimo com relação à ciência e absolutamente nada com relação à matemática”.

Nessa circunstância, o conhecimento produzido ou em circulação no país, ainda era reflexo daqueles dos grandes impérios europeus dos séculos XVI, XVII e XVIII transmitiam. Esses conhecimentos foram absorvidos e transformados nas colônias e nos novos países independentes. Confirmando a assertiva, D’Ambrosio (1999, p.9) postula que "os países periféricos não participaram do progresso da matemática antes do final do século XIX. Até então se deu apenas a recepção do conhecimento matemático e não sua elaboração". O autor denomina países periféricos aqueles que a partir dos grandes descobrimentos passaram a ser receptores do conhecimento produzido nos países centrais, a complexidade da era colonial.

Conforme aponta Valente (1999), a disciplina de Matemática existe desde 1931 na escola e a partir de então que vai se consolidar como disciplina. Esse desenvolvimento da Matemática se deu pela impulsão do ensino e do saber científico.

\section{Tratamento dado a disciplina Matemática}

Sabe-se que havia pouca preocupação em relação aos diferentes campos da matemática, os quais eram divididos em aritmética, trigonometria, álgebra e geometria. Foi 
com a proposta apresentada por Euclides de Medeiros Guimarães Roxo (1931), com base na reforma realizada por Felix Klein na Alemanha, que o ensino da Matemática passou por uma grande mudança, onde o ponto principal seria em acabar com a matemática ensinada em partes distintas e separadas (aritmética, álgebra e geometria), ensinando-as conjuntamente sob o nome de matemática.

Anterior a reforma, os alunos cursavam aritmética, álgebra, geometria $\mathrm{e}$ trigonometria separadamente na escola. Nesse ínterim, Valente (1999, p. 111) aponta que “a matemática, salvo o conhecimento mais que elementar da Aritmética, estava reservada para a formação técnica do futuro engenheiro, guarda-marinho, etc. Tratava-se, portanto, de um saber técnico e especializado”.

O objetivo da formação nas escolas primárias para o período era ensinar a ler, escrever e contar conforme expresso na Lei 15 de Outubro. Valente (1999), expressa que baseada no trabalho de Condorcet, na primeira escolarização, na proposta de ensino para a matemática os alunos "no primeiro ano deveriam aprender sistema de numeração, no segundo as quatros operações aritméticas e 'as primeiras noções de geometria, particularmente as que forem necessárias à medições de terrenos' e, além disso, haveria necessidade de 'exercitar o menino em traçar figuras já a mão, já com o compasso e régua” (VALENTE, 1999, p. 111).

Como a tentativa de inserir o ensino de geometria na educação primária gerou polemica e por alguns entraves como a falta de professores primários habilitados e a razão do conhecimento não ser considerado pré-requisito para ingresso em nenhuma instituição de ensino secundário, o ensino de geometria ficou reservado a escola secundária.

Poderíamos até aqui inferir que a Matemática ensinada era estritamente prática e ensinava quase exclusivamente a escrita dos números e as operações, mesmo assim, destinado apenas a uma pequena elite.

Outra questão importante no ensino de matemática refere-se à utilização dos livros didáticos. Esses eram traduzidos de autores europeus e serviam apenas para os professores. Vale destacar, que até o ano de 1830 não existia livro didático produzido no país. As primeiras obras didáticas nacionais tiveram como precursores os trabalhos de Cândido Baptista de Oliveira, Francisco de Paula Leal e Pedro de Alcântara Bellegarde, sendo os dois últimos destinadas aos liceus provinciais.

A Aritmética de Cândido Baptista de Oliveira ${ }^{95}$ serviu como referência para uso nas escolas primárias. O texto foi escrito para professores-instrutores e sua estrutura compreendia

\footnotetext{
95 Era professor da Escola Politécnica do Rio de Janeiro, foi o primeiro proponente da adoção do sistema métrico decimal pelo Brasil. Ocupou vários cargos públicos e criou, em 1859, a Revista Brazileira, voltada para as ciências, letras e artes, publicada entre 1857 e 1861 . Disponível em https://www.researchgate.net/profile/Luisa_Massarani/publication/268256235_CANDIDO_BATISTA_DE_OLI VEIRA_E_SEU_PAPEL_NA_IMPLANTACAO_DO_SISTEMA_METRICO_DECIMAL_NO_BRASIL/links/555d ISSN 2526-2882

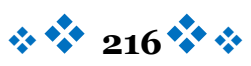


de um conjunto de tabelas que o autor vai ao longo do texto explicando como utilizar cada uma, como menciona no prefácio da obra:

Com efeito, bastará que o professor, munido deste Compêndio, trace em um painel, segundo a ordem das lições, as tabelas que nela se contêm explicandoas pela maneira indicada nas notas correspondentes, às quais, sendo fielmente copiadas pelos alunos, reproduzirão, nas mãos destes, toda a doutrina útil que ele encerra, logo que terminada seja a sua exposição (VALENTE, 1999, p.124).

Foi nas últimas décadas do século XIX que uma grande quantidade de livros didáticos das matemáticas passou a ser editados. Valente (1999) dá destaque aos livros de Antonio Trajano ${ }^{96}$, o qual considera suas obras como best-sellers. Das duas obras de Trajano, Aritmética Elementar Ilustrada foi destinada ao ensino primário e Aritmética Progressiva destinada ao ensino secundário (escolas normais e liceus particulares). Valente (1999, p.165) afirma que "o grande diferencial dos livros de Trajano situa-se na forma didática do texto. A teoria é sempre posta por meio de exemplos numéricos, seguidos de exercícios resolvidos, com explicação passo a passo do que o aluno deverá realizar”.

Das informações apresentadas por Valente pode afirmar que o didático destinado à escola primária Aritmética Elementar Ilustrada, perdurou por mais de meio século como base para professores. O livro lançado em 1879 alcançou a 136 ${ }^{\mathrm{a}}$ edição no ano de 1958. Trajano, pode ter sido o introdutor do livro do professor, no ensino de matemática. (VALENTE, 1999)

\section{Considerações}

Por um longo período na história da educação desse país, os conhecimentos matemáticos contemplavam o ensino da escrita dos números no sistema de numeração decimal e o estudo das operações de adição, subtração, multiplicação e divisão de números naturais. Em alguns casos, o conteúdo matemático era negligenciado.

É somente com a instituição das escolas de primeiras letras, no período imperial que a Matemática passou a estar presente. Nessas escolas se ensinavam "ler, escrever e contar".

Foi no início da República que o ensino primário teve de um novo modelo de organização, o dos grupos escolares, tendo o estado São Paulo como pioneiro na implantação deste modelo em 1893 e que logo se difundiu pelos outros estados. Os grupos escolares

c10408ae8cocab2af57e/CANDIDO-BATISTA-DE-OLIVEIRA-E-SEU-PAPEL-NA-IMPLANTACAO-DOSISTEMA-METRICO-DECIMAL-NO-BRASIL.pdf acesso em 18 abr. 2019

${ }^{96}$ António Trajano nasceu em Portugal. Publicou as primeiras aritmética e álgebra para uso dos cursos primário e secundário do Brasil. Seus livros foram oficialmente adotados pela Família Real Brasileira. Alguns exemplos de tais publicações foram apresentados pela Editora Francisco Alves como: Álgebra Elementar; Chave de Álgebra; Álgebra superior; Aritmética Primária; Aritmética Progressiva; Chave de Aritmética Progressiva; e Aritmética Elementar Ilustrada. (TORRES, 2013, p.57) 
reuniam as classes em séries, estruturadas com alunos separados por séries, com um professor, e grupos de quatro ou cinco séries reunidos em um mesmo prédio.

Os Grupos Escolares permitiram a possibilidade de participação da mulher na sociedade, uma vez que tais escolas foram divididas em seções masculina e feminina e reafirmou o status do professor na sociedade.

A princípio, os Grupos Escolares atenderam aos alunos das camadas elitistas e, mais tarde, a partir da década de 1950, abriram suas portas para a sociedade economicamente desprovida, devido à demanda pela escolarização. No entanto, os pobres, os negros e os miseráveis ficaram excluídos.

O regime Republicano, especificamente, na década de 1920, num contexto de profundas mudanças políticas, econômicas e sociais, realizaram-se, no país várias reformas no sistema de ensino relativas à educação primária e à formação de professores e essas reformas vinculavam-se ao movimento pedagógico conhecido, entre outras denominações, como Escola Nova ou Escola Ativa.

Os princípios escolanovistas, segundo Vidal (2003) baseia-se na "centralidade da criança nas relações de aprendizagem, o respeito às normas higiênicas na disciplinarização do corpo do aluno e de seus gestos, a cientificidade da escolarização de saberes e fazeres sociais e a exaltação do ato de observar, de intuir, na construção do conhecimento do aluno”. E acrescida as ideias fundamentais, destacada Miorim (1998, p.90) o "princípio da atividade" e o "princípio de introduzir na escola situações da vida real", trouxeram mudanças no ensino primário, com reflexos específicos na abordagem da Matemática.

\section{Referências}

ARANHA, M L de A. História da educação. $2^{\text {a }}$ ed. rev. e atual. São Paulo: Moderna, 2006. AZEVEDO, C B de; SANTOS, R M dos. Vitrine do ensino primário no início do século XX: os grupos escolares do Rio Grande do Norte em forma de celebração. Revista Crítica Histórica. Alagoas SE: Universidade Federal de Alagoas, Ano VIII, nº 16, dezembro, 2017.

. Lei $\mathrm{n}^{\mathrm{o}}$ 1006/1913. Reforma o Ensino primário. Disponível em https://repositorio.ufsc.br/handle/123456789/122531 Acesso em 20 abr. 2019.

BRASIL, LEI DE 15 DE OUTUBRO DE 1827. Disponível em http://www.planalto.gov.br/ccivil_03/leis/lim/LIM-15-10-1827.htm acessado em 28 mar 2017

CHERVEL, A. História das Disciplinas Escolares. Revista Teoria e Educação. Porto Alegre, RS: Pannonica, 1990, nº 2, p. $177-229$. 
D`AMBROSIO, U. História da matemática no brasil uma visão panorâmica até 1950. Saber y Tiempo, vol. 2, $n^{\circ} 8$, Julio-Deciembre, 1999; p. 7-37.

GILES, T R. História da educação. São Paulo: EPU, 1987.

GHIRALDELLI Junior, P. História da Educação. 2. ed. São Paulo: Cortez, 1994.

JULIA, D. A Cultura Escolar como Objeto Histórico. Revista Brasileira de História da Educação. Campinas. Editora Autores Associados. No 1, jan./jun. 2001, pp. 9 - 43.

MATOS E SILVA, R V. A sócio-história do Brasil e a heterogeneidade de português brasileiro: algumas reflexões. Boletim da ABRALIN, n.17, p.73-85, jun 1985.

MIORIM, M Â. Introdução à História da Educação Matemática. São Paulo: Atual, 1998 PINHEIRO, A C F. Da era das cadeiras isoladas à era dos grupos escolares na Paraíba. Campinas, SP: Autores Associados, São Paulo: Universidade São Francisco, 2002

SAVIANI, D. O legado educacional do "longo século XX" brasileiro. In: SAVIANI, Dermeval (et. al.). $O$ legado educacional do século XX no Brasil. $2^{\text {a }}$ ed. Campinas, SP: Autores Associados, 2006

SILVA, C P da. A MATEMÁTICA NO BRASIL: Uma História de seu Desenvolvimento. Disponível em http://www.accefyn.org.co/PubliAcad/Clovis/titular/titular.html. Acessado em jul de 2017.

. História das ideias pedagógicas no Brasil. 3. ed. rev. Campinas, SP: Autores Associados, 2010.

SOUZA, R F de. Lições da escola primária. In: SAVIANI, Dermeval (et. al.). O legado educacional do século XX no Brasil. $2^{\text {a }}$ ed. Campinas, SP: Autores Associados, 2006.

. História da organização do trabalho escolar e do currículo no

século XX. Ensino primário e secundário no Brasil. São Paulo: Cortez, 2008.

. Templos de civilização: a implantação da escola primária graduada no Estado de São Paulo (1890-1910). São Paulo: Fundação Editora da UNESP, 1998.

TORRES, M A G. Análise histórica e metodológica do Livro de António Trajano e suas relações com os atuais Parâmetros Curriculares Nacionais (PCN). Dissertação de Mestrado. Programa de Pós-Graduação em Educação, Universidade Federal de Viçosa, 2013.

VALENTE, W R. Uma história da matemática escolar no Brasil, 1730-1930. São Paulo: Annablume: Fapesp, 1999.

VIDAL, D. Escola nova e processo educativo. In: LOPES, E. M.; FARIA FILHO, L. M.; VEIGA, C. G. (Orgs.) 500 anos de Educação no Brasil.3. ed. Belo Horizonte: Autêntica, 2003.

ISSN 2526-2882

$$
\text { * } 219
$$




\section{Biografia Resumida}

Zenildo Santos: Professor da Educação Básica, possui graduação em Letras vernáculas pela Universidade do Estado da Bahia (2007), graduado em Literatura e Ensino de Literatura, pela Universidade Estadual do Sudoeste da Bahia (2011), graduação em Matemática pela Universidade Estadual do Sudoeste da Bahia (2017) e mestrado em Ciências e Matemática Universidade Estadual do Sudoeste da Bahia (2019).

Link Lattes: http://Link Lattes.cnpq.br/3266291362839017

e-mail: zenildo198090@gmail.com

Claudinei de Camargo Sant 'Ana: Possui graduação em Licenciatura em Matemática pela Pontifícia Universidade Católica de Campinas, PUC-Campinas (1988), em Pedagogia pela Faculdade de Ciências e Letras Plínio Augusto do Amaral, FCLPAA (1990), e especialista em Informática em Educação pela Universidade Federal de Lavras, UFLA (2007), mestrado em Engenharia Mecânica pela Universidade Estadual de Campinas, Unicamp (1995), doutorado em Educação pela Universidade Estadual de Campinas, Unicamp (2008), em 2010 realizou estágio de pós-doutoramento na Universidade Estadual Paulista Júlio de Mesquita Filho, UNESP/Rio Claro; em 2016 realizou estágio de pós-doutoramento na Université de Limoges Faculté des Sciences et Techniques, Limoges/França. Lecionou em instituições de ensino fundamental, médio e superior. Editor da Revista Eletrônica "Com a Palavra, o Professor", e atualmente é professor Titular da Universidade Estadual do Sudoeste da Bahia, trabalha nos cursos de Matemática, Pedagogia e orienta dissertações de Mestrado no Programa de Pós-Graduação Educação Científica e Formação de Professores (PPG-ECFP), no Programa de Pós-Graduação em Ensino (PPGEn). Atualmente é membro da comissão científica da Sociedade Brasileira de Educação Matemática na Bahia, SBEM/Ba. Tem experiência na área de Educação, com ênfase em Educação Matemática, Educação a Distância; atuando principalmente nos seguintes 
temas: Aprendizagem da Matemática, História do Ensino da Matemática, Tecnologia Informática e Formação de Professores. Link Lattes: http://Link Lattes.cnpq.br/2970320445020239 e-mail: claudinei@ccsantana.com 